\title{
Efficacy of CR3294, a new benzamidine derivative, in the prevention of 5-fluorouracil-induced gastrointestinal mucositis and diarrhea in mice
}

\author{
Ornella Letari · Catherine Booth • Albino Bonazzi • \\ Paolo Garofalo $\cdot$ Francesco Makovec • \\ Lucio C. Rovati · Gianfranco Caselli
}

Received: 25 September 2009/Accepted: 13 December 2009/Published online: 30 December 2009

(C) The Author(s) 2009. This article is published with open access at Springerlink.com

\begin{abstract}
Purpose Gastrointestinal mucositis, commonly associated with diarrhea, is a dose-limiting toxicity of chemotherapy. The new benzamidine derivative CR3294 reduces tissue damage in animal models of intestinal inflammation. Thus, we tested whether CR3294 had the potential to prevent chemotherapy-induced mucositis.

Methods In tests on isolated cells, reactive oxygen species (ROS) formation and cytokine release were measured by chemiluminescence and immunoassays, respectively. In studies in vivo, BDF1 mice were given oral CR3294 (2.5$20 \mathrm{mg} / \mathrm{kg}$ ) for 3 days before receiving 5-fluorouracil. Intestinal crypt survival, cell apoptosis and proliferation, and diarrhea score were assessed. Additionally, nude mice bearing tumor xenografts were treated with CR3294 and/or 5 -fluorouracil, and tumor growth was monitored.

Results CR3294 significantly inhibited cytokine release from stimulated leukocytes at concentrations similar to the $\mathrm{IC}_{50}(2.9 \pm 0.2 \mu \mathrm{M})$ for ROS production by these cells. Consistent with these molecular findings, CR3294 dosedependently protected the intestinal mucosa against 5-fluorouracil-induced toxicity in a mouse model of mucositis. The number of surviving crypts per cross-section in mice receiving $20 \mathrm{mg} / \mathrm{kg}$ CR3294 was 2.8-fold that in vehicle-treated animals
\end{abstract}

O. Letari · P. Garofalo · F. Makovec · G. Caselli ( $₫)$

Department of Pharmacology and Toxicology,

Rottapharm S.p.A., via Valosa di Sopra 9,

20052 Monza, Italy

e-mail: gianfranco.caselli@rottapharm.com

C. Booth

Epistem Ltd., 48 Grafton Street, Manchester M13 9XX, UK

A. Bonazzi · L. C. Rovati

Department of Clinical Pharmacology, Rottapharm S.p.A.,

via Valosa di Sopra 9, 20052 Monza, Italy
$(18.1 \pm 1.9$ vs. $6.5 \pm 0.9, P<0.001)$. Moreover, CR3294 decreased the cumulative diarrhea score by $50 \%$, reduced by nearly $70 \%$ the incidence of severe episodes, and increased by 3 -fold the number of mice without diarrhea. CR3294 neither affected the growth of tumor xenografts nor protected tumors from the cytotoxic activity of 5-fluorouracil.

Conclusions This study demonstrates that CR3294 acts on key molecular targets to reduce the signs of mucositis and the occurrence of diarrhea in mice exposed to the chemotherapy drug 5-fluorouracil.

Keywords CR3294 - Mucositis - Chemotherapy · Diarrhea $\cdot$ Cancer

\section{Introduction}

Chemotherapy and radiation therapy are useful for treating many forms of cancer. However, they also affect rapidly dividing cells in healthy tissues, in particular the epithelial cells of the alimentary tract. This is the reason why oral and gastrointestinal (GI) mucositis commonly arises as an adverse effect of anticancer therapy and often causes dose delays or reductions, which can hamper treatment success [1-3].

GI mucositis is associated with many chemotherapy protocols and with radiotherapy directed to any part of the GI tract. These treatments kill progenitor cells in the crypts of Lieberkühn, at the base of the villi, with consequent breakdown of the mucosal barrier [1]. Diarrhea is one of the most common manifestations of GI mucositis. The incidence and severity of diarrhea vary greatly, depending on the therapeutic regimen chosen. Chemotherapy-induced diarrhea (CID) occurs in as many as $80 \%$ of patients with cancer treated with 5-fluorouracil (5-FU) and irinotecan. Of even greater concern, increased death rates from GI 
toxicity have been reported in patients receiving irinotecan plus bolus 5-FU/leucovorin [3-7]. As the impact of CID rises with the advent of more aggressive anticancer therapies, new therapeutic options for preventing GI mucositis and diarrhea are awaited [5, 6, 8, 9].

CR3294 belongs to a novel series of anti-inflammatory agents that inhibit the expression of inducible nitric oxide synthase (iNOS). Notably, this compound protects the epithelium from injury in validated animal models of GI inflammation [10, 11]. Mucositis is now regarded as a complex phenomenon in which many cellular and tissue components of the mucosa play a part. In essence, reactive oxygen species (ROS) activate downstream signaling pathways, transcription factors mediate the expression of target genes such as interleukin (IL)- $1 \beta$, IL-6, and tumor necrosis factor- $\alpha(\mathrm{TNF}-\alpha)$, and these cytokines fuel a vicious loop that harms mucosal integrity [12-15]. On the basis of the evidence available and because of the unmet medical need, CR3294 was tested as a preventive agent against mucositis.

The aims of this study were to provide in vitro data that support a role for CR3294 in reducing the molecular triggers for mucositis and to assess, in a relevant animal model, whether CR3294 has the potential to prevent GI mucositis and diarrhea.

\section{Materials and methods}

\section{Materials}

CR3294, N-[4-[[(pentylamino)thioxomethyl]amino]phenyl]ethanimidamide, monohydrochloride, was synthesized by the Medicinal Chemistry Department of Rottapharm S.p.A. (Monza, Italy). Phorbol-12-myristate-13-acetate (PMA), luminol, HISTOPAQUE-1077, and lipopolysaccharide (LPS) were from Sigma (Milan, Italy); dextran T500 was from Amersham Pharmacia Biotech (Uppsala, Sweden); and multiplex human cytokine kits were from Bio-Rad (Milan, Italy). All general purpose reagents used in animal studies were from Sigma-Aldrich (Poole, UK). Animals were purchased from Harlan Laboratories UK Ltd., and tumor cell lines were from the American Type Culture Collection (ATCC). We purchased 5-FU from Roche (Welwyn Garden City, UK). Rat anti-5-bromo-2'-deoxy-uridine (BrdU) clone U1/75 (ICR1) antibody was from AbD SeroTec MorphoSys UK Ltd., with labeling detected using the ABC Elite system from Vector Laboratories UK Ltd.

In vitro studies

\section{ROS production by human polymorphonuclear leukocytes (neutrophils)}

Venous blood was collected from healthy human donors in sodium citrate $0.38 \%$ and centrifuged at $275 \mathrm{~g}$ for $15 \mathrm{~min}$.
The resulting buffy coat was diluted 3 times (3-9 $\mathrm{mL}$ ) with phosphate-buffered saline (PBS) and mixed with $2 \mathrm{~mL}$ of $6 \%$ dextran T500 in $0.9 \%$ saline. This mixture was left for $45 \mathrm{~min}$ at room temperature, then the supernatant was collected and centrifuged at $275 \mathrm{~g}$ for $15 \mathrm{~min}$. The pellet (leukocytes) was subjected to hypotonic lysis of contaminating erythrocytes by addition of distilled water. The osmolarity was restored with $0.8 \% \mathrm{NaCl}$ solution. Leukocytes were then centrifuged at $275 g$ for $15 \mathrm{~min}$ and washed again in PBS. Polymorphonuclear leukocytes (PMNL) were isolated by gradient centrifugation ( $400 \mathrm{~g}$ for $30 \mathrm{~min}$ ) on HISTOPAQUE-1077. Purified PMNL were suspended in PBS plus $0.87 \mathrm{mM} \mathrm{CaCl}_{2}$ and $1 \mathrm{mM} \mathrm{MgCl} 2$, counted, and diluted to $2.5 \times 10^{6}$ cells $/ \mathrm{mL}$. For chemiluminescence assays, the PMNL suspension was premixed with luminol (5 $\mu \mathrm{M}$ final). Aliquots of cell suspension $(200 \mu \mathrm{L})$ were incubated with CR3294 $(1,3$, or $10 \mu \mathrm{M})$ or its vehicle (distilled water) for $10 \mathrm{~min}$ at $37^{\circ} \mathrm{C}$. Next, PMNL were activated with $0.1 \mu \mathrm{M}$ PMA, and light emission was monitored at 3-min intervals for $24 \mathrm{~min}$ in a HTS7000 plus microplate reader. Results are expressed as relative luminescence units (RLU).

Cytokine release from peripheral blood mononuclear cells

Peripheral blood mononuclear cells (PBMC) were isolated by density gradient centrifugation on HISTOPAQUE-1077, according to the manufacturer's instructions. Purified cells were resuspended in RPMI-1640 culture medium containing $1 \%$ fetal bovine serum and adjusted to $2 \times 10^{6}$ cells $/ \mathrm{mL}$. Aliquots of cell suspension $(200 \mu \mathrm{L})$ were added to duplicate wells of a flat-bottom 96-well plate containing CR3294 or vehicle (distilled water) and incubated for $1 \mathrm{~h}$ at $37^{\circ} \mathrm{C}$ in a humidified atmosphere of $5 \% \mathrm{CO}_{2}$. Cytokine synthesis was induced by a 4-h stimulation with $1 \mu \mathrm{g} / \mathrm{mL}$ LPS (from E. coli, serotype $0127 \mathrm{~B} 7)$. To rule out cytotoxic effects, parallel plates were tested for viability by MTT [3-(4, 5-dimethylthiazol-2-yl)-2,5-diphenyltetrazolium bromide] assay. At the end of the incubation period, supernatants were collected and assayed for IL- $1 \beta$, TNF- $\alpha$, IL- 6 , and IL- 8 by Bio-Plex technology (BioRad, Milan, Italy) according to the recommended procedures. Data were analyzed using the Bio-Plex Manager ${ }^{\mathrm{TM}}$ software from Bio-Rad (version 4.0), and results are given as $\mathrm{IC}_{50}$ values $(\mu \mathrm{M})$.

In vivo studies

\section{Ethics and animal care}

All studies were conducted in accordance with the UK Home Office Animals (Scientific Procedures) Act 1986, at standards equivalent to the UKCCCR guidelines for the welfare of animals in experimental neoplasia [16]. Animals 
were held in individually ventilated cages in a specific pathogen-free barrier unit. On arrival from the supplier, mice were housed for 2 weeks to enable acclimatization and stabilize the circadian rhythm. Mice were identified by numbered cages and by ear punches. There was a constant room temperature of $21 \pm 2{ }^{\circ} \mathrm{C}$ and a mean relative humidity of $55 \pm 10 \%$. The day-night cycle was constant, with light and dark phases of $12 \mathrm{~h}$ each. Both feed and water (from drinking bottles) were available ad libitum. Animal health was monitored daily and cages were cleaned at regular intervals.

\section{Analysis of intestinal crypt survival}

Male BDF1 mice (10-12 weeks of age, $n=8$ per group) were used in this experiment. CR3294 was stored at room temperature in the dark: solutions were prepared fresh each day in deionized water, and concentrations were adjusted to give the appropriate dose $(2.5,5,10$, or $20 \mathrm{mg} / \mathrm{kg})$ in $100 \mu \mathrm{L}$. Intestinal damage was induced by either 5 -FU $(2 \times 450 \mathrm{mg} / \mathrm{kg}$ intraperitoneally, $6 \mathrm{~h}$ apart $)$ or irradiation (13 Gy) on day 0 of the study, after 3 days of once-daily oral administration of CR3294 or its vehicle. Irradiation was administered by a Pantak HF320 X-ray unit (Agfa NDT Ltd., Reading, UK). The machine was operated at $300 \mathrm{kV}, 10 \mathrm{~mA}$. The X-ray tube was fitted with additional filtration to give a radiation quality of $2.3-\mathrm{mm} \mathrm{Cu}$ halfvalue layer (HVL). Mice were restrained in a jig positioned at a distance of $700 \mathrm{~mm}$ from the focus of the X-ray tube, and irradiation was delivered at a dose rate of $70 \mathrm{cGy} / \mathrm{min}$.

An examination of body weight, general condition, behavior, and mortality was performed daily for each mouse. Animals were killed 4 days after the last dose of the cytotoxic insult. The small intestine was removed, fixed in Carnoy's fixative, paraffin embedded, and processed for histology with hematoxylin and eosin (H\&E) stain. Ten intestinal circumferences per mice were analyzed. The number of surviving crypts per circumference was scored and the group mean was determined [17, 18]. Only crypts containing 10 or more strongly H\&E-stained cells (excluding Paneth cells), only intact circumferences not containing Peyer's patches, were scored. The mean crypt width (at its widest point) was also measured to correct for scoring errors due to crypt size differences [19]. The following correction was applied:

Corrected number of crypts per circumference $=$

(mean crypt width in untreated controls/mean

crypt width in treatment group)

$\times$ mean number of surviving crypts in treatment group.

The effects of CR3294 were also expressed as Protection Index, i.e., the ratio of surviving crypts in treatment group to surviving crypts in vehicle control group.

\section{Cell proliferation and apoptosis}

Male BDF1 mice (10-12 weeks of age, $n=6$ per group) were randomized into 7 groups and divided into 2 experiments. In the first one, we tested the effect of CR3294 $(20 \mathrm{mg} / \mathrm{kg})$ on crypt cell proliferation $24 \mathrm{~h}$ after 3 daily doses (i.e., the time at which 5-FU is administered). Animals were dosed with $10 \mathrm{mg}$ of $\mathrm{BrdU}(0.5 \mathrm{~mL}$ intraperitoneally) $40 \mathrm{~min}$ before killing. In the second experiment, we examined the levels of apoptosis $4.5 \mathrm{~h}$ after exposure to single or repeated ( 2 times, $6 \mathrm{~h}$ apart) cytotoxic doses of 5 -FU $(450 \mathrm{mg} / \mathrm{kg})$. Mice were killed by cervical dislocation in both studies. The small intestine was removed, fixed in Carnoy's fixative, paraffin embedded, and sectioned to generate 2 non-serial sections per slide. Carnoy's fixed sections were either labeled to reveal BrdU incorporation or $\mathrm{H} \& \mathrm{E}$ stained to measure the incidence of apoptosis. Crypts were analyzed on a cell positional basis to identify drug-induced changes. In all cases, 50 half-crypts per mouse were scored-300 scores per group, from which the frequencies were generated [20]. Quantification of BrdU labeling and apoptosis was performed by the purpose-built WinCrypts software program, which analyzes the statistical significance of any distributions using an extension of the median test. At each cell position, the common median for all the animals was calculated, and then the individual values for each animal were classified as being below or above the median [21].

\section{Diarrhea assessment}

Male BDF1 mice (10-12 weeks of age, $n=15$ per group) were randomized into 2 groups. Dosage regimens for 5-FU and CR3294 $(20 \mathrm{mg} / \mathrm{kg})$ were consistent with those used in the experiments described earlier. Mice were weighed once-daily after the beginning of treatment. Similarly, animal well-being was checked daily, and the incidence and severity of diarrhea were scored. Checks increased to twice a day during days $4-11$. Scores were recorded as 0,1 , 2 , or 3 where 0 is normal stool consistency, 1 is loose stools, 2 is overt diarrhea, and 3 is liquid feces with severe perianal/tail soilage (extreme diarrhea). Surviving animals were to be killed 20 days after the cytotoxic insult.

\section{Tumor proliferation models}

Two experiments were carried out to rule out adverse effects of CR3294 on tumor growth or 5-FU activity. In the first study, 16 male and 16 female BALB/c nude mice were xenografted with human colorectal (HT29) and breast 
(MDA-MB-231) cancer cells, respectively. Tumors were measured with calipers 3 times per week and were allowed to grow until the mean tumor volume of the group reached $100-150 \mathrm{~mm}^{3}$. Animals were treated with $20 \mathrm{mg} / \mathrm{kg}$ CR3294 or vehicle (sterile water) daily for 14 days. In the second study, 32 male BALB/c nude mice were xenografted with the colorectal HT29 cell line and randomized into 4 treatment groups. Groups 2 and 4 were treated with oral CR3294 on days 1-3 and 8-10 (incorporating a 5-day interval). The cytotoxic treatment $(5-\mathrm{FU}, 25 \mathrm{mg} / \mathrm{kg}$ intraperitoneally) was administered on days $1-5$ in group 4 as well as in cytotoxic control group 3. The dual vehicle control group (group 1) was administered with the test agent vehicle (water) on days 1-3 and 8-10 and with the 5FU vehicle (saline) on days 1-5. All the mice in both studies were weighed 3 times per week. Well-being was checked daily: any animal with more than $15 \%$ weight loss was considered unwell and killed if the weight loss was greater than $20 \%$. If an animal became unwell, any treatment of that animal was suspended. If there was no recovery, the mouse was killed. Tumor sizes were measured for up to 28 days after the first dose of CR3294 or vehicle.

\section{Statistics}

For the evaluation of statistical differences between experimental groups, one- or two-way analysis of variance (ANOVA) followed by Holm-Sidak test for multiple comparisons were used. Data without homogeneity of variance were analyzed with Mann-Whitney rank sum test or Kruskal-Wallis one-way ANOVA, and multiple post hoc comparisons were performed using Dunn's method. In studies of proliferation and apoptosis, the common median for all the animals (at each cell position in the crypt) was calculated. Next, the individual values for each animal were classified as being below or above the median, and the chi-squared test was applied on the tabulated frequencies. All analyses were done with the SigmaStat version 3.5 software, and a significance level of 0.05 was used throughout.

\section{Results}

In vitro studies

First, we tested the hypothesis that CR3294 has the ability to inhibit key molecular events in the onset of mucositis. In these in vitro studies, we used human PMNL and PBMC because leukocytes are a rich source of both ROS and cytokines.

Phorbol-12-myristate-13-acetate (PMA) rapidly increased ROS production by PMNL, as measured by chemiluminescence. CR3294 inhibited this response in a concentration dependent manner, with an $\mathrm{IC}_{50}$ value of $2.9 \pm 0.2 \mu \mathrm{M}$ and a maximal inhibition of about $76 \%$ at $10 \mu \mathrm{M}$. The effects of treatment and time, and their interaction, were all significant $(P<0.01$, two-way ANOVA). Post hoc analysis showed significant differences across all groups from 6 min onward (Fig. 1).

To assess the impact of CR3294 on cytokine release, human PBMC were stimulated with $1 \mu \mathrm{g} / \mathrm{mL}$ LPS for $4 \mathrm{~h}$. Under these conditions, CR3294 concentration-dependently inhibited the release of TNF- $\alpha$, IL- 6 , and IL- 8 . The $\mathrm{IC}_{50}$ values ranged between 6 and $9 \mu \mathrm{M}$. Moreover, CR3294 potently inhibited the release IL- $1 \beta$, with an $\mathrm{IC}_{50}$ of about $100 \mathrm{nM}$. Similar results were obtained in two independent experiments, each done in duplicate, and significant inhibitions were generally seen at concentrations of $3 \mu \mathrm{M}$ or higher.

In vivo studies

\section{Effects of CR3294 on the mucosal epithelium}

Next, we studied whether orally administered CR3294 could protect crypt cells in the intestinal mucosa against damage induced by chemotherapy or radiation. We tested

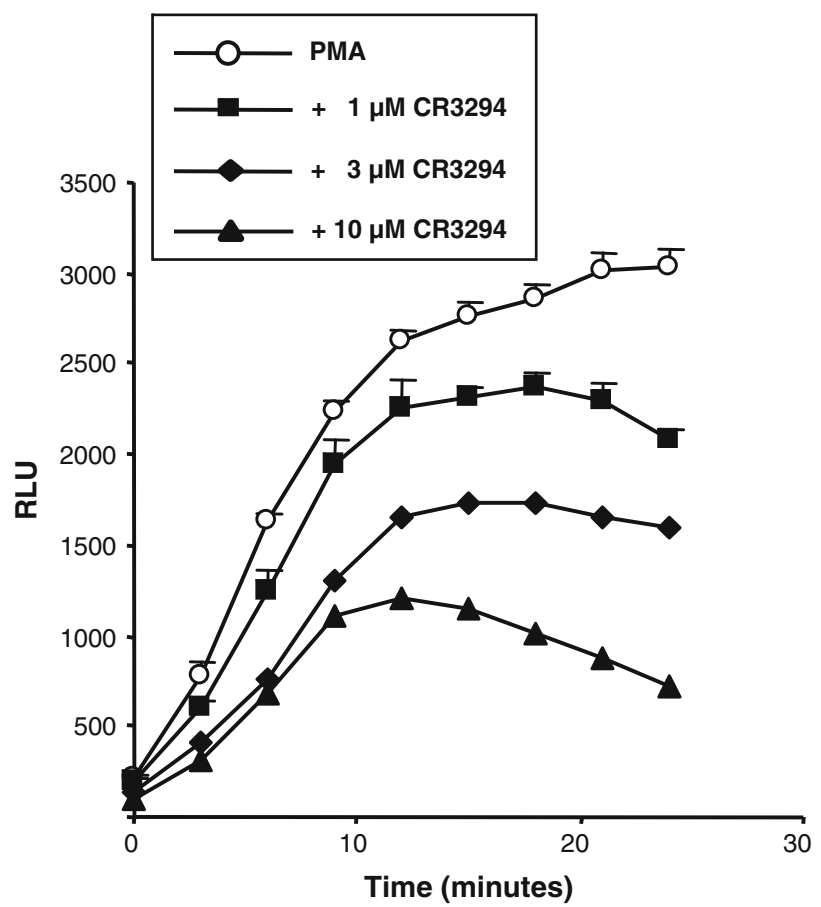

Fig. 1 Effects of increasing concentrations of CR3294 on ROS production by PMNL stimulated with PMA. Between-group differences are all $P<0.05$ from 6 min onward (Holm-Sidak method). Similar results were obtained in 3 independent experiments performed in quadruplicate. ROS reactive oxygen species, $P M N L$ polymorphonuclear leukocytes, $P M A$ phorbol-12-myristate-13-acetate, $R L U$ relative luminescence units 
different dosing schemes and found that CR3294 was especially effective when given as a preventive measurei.e., 72,48 , and $24 \mathrm{~h}$ before cytotoxic treatment. Under these conditions, none of the animals receiving 5-FU died before the scheduled killing time (4 days after the last dose of 5-FU). All mice, except those in the untreated control group, lost weight to similar extents and with similar kinetics (not shown). CR3294 protected the mucosa against 5-FU-induced toxicity, and there was a clear dose-response effect. The corrected number of surviving crypts per circumference in the group treated with $20 \mathrm{mg} / \mathrm{kg}$ CR3294 was nearly 3 -fold that in vehicle-treated mice $(18.1 \pm 1.9$ vs. $6.5 \pm 0.9$, Protection Index 2.8, $P<0.001$; Table 1). Conversely, no conclusive effects of CR3294 were seen in a model of radiation-induced mucositis. The Protection Index ranged from 1 to 1.9 in three different experiments, and there was no clear dose-response relationship.

More experiments were run to determine whether CR3294 protected the epithelium by increasing cell proliferation or by decreasing the sensitivity of crypt cells-either all cells or a particular cell type in the crypt hierarchy-to 5-FU-induced apoptosis. As expected, sections of small intestine from control mice showed high levels of proliferation: about half of the cells in the mid-crypt region were labeled with BrdU. Twenty-four hours after the last dose of CR3294 (20 mg/kg), there were no significant changes in the frequency or distribution of BrdU labeling (Fig. 2a). One or two doses (6 h apart) of 5-FU induced progressively higher rates of crypt cell apoptosis. Pretreatment with $20 \mathrm{mg} / \mathrm{kg}$ of CR3294 did not affect the levels of apoptosis induced by 5-FU (Fig. 2b).

\section{Effect of CR3294 on 5-FU-induced diarrhea}

We then assessed in a proof-of-concept study whether CR3294, at the dose $(20 \mathrm{mg} / \mathrm{kg})$ that significantly decreased mucosal damage, also reduced the incidence and/or severity of diarrhea in mice exposed to 5-FU. Nearly all mice (13 out of 15 ) receiving 5-FU and vehicle developed diarrhea starting from day 4 . The number of mice without diarrhea for the entire study was 3-fold higher in the group treated with CR3294 than in vehicle-treated animals. Moreover, pretreatment with CR3294 reduced the cumulative symptom score by $50 \%$ (Fig. 3). Moderate-tosevere diarrhea (grade 2-3) was more frequent in the vehicle-treated group than in the group treated with CR3294 (13 vs. 4 observations; nearly 70\% reduction). Similar results were found when we analyzed the 7-day study period during which all mice were alive (Fig. 4). Statistical analysis showed a significant difference $(P<0.05$, Mann-Whitney rank sum test) between the two groups in the median diarrhea score.

Animals died between days 8 and 13 after 5-FU challenge. Thus, CR3294 did not improve survival, although the onset of death was slightly delayed in the group receiving the active treatment (4 deaths during days 8 and 9 vs. 7 deaths during the same period in the vehicle-treated group).

\section{Tumor proliferation models}

To rule out adverse effects of CR3294 on tumor growth or 5-FU activity, we finally undertook two studies in xenograft models of human colorectal (HT29)/breast (MDA-MB-231) cancer. In the first study, the mean volume of HT29 and MDA-MB-231 tumors grew about 10- and 7-fold, respectively, over 1 month. Two weeks of treatment with CR3294 $20 \mathrm{mg} / \mathrm{kg}$ once-daily had no effect on the rate of tumor growth (Fig. 5a, b) and did not affect animal weight. In the second study, 5-FU inhibited the growth of HT29 xenografts, and CR3294 did not hamper the response to the chemotherapy drug (Fig. 6).

Table 1 Effect of pretreatment with CR3294 on 5-FU-induced intestinal crypt death

\begin{tabular}{lcc}
\hline Pretreatment $^{\mathrm{a}}$ & $\begin{array}{l}\text { Surviving crypts per } \\
\text { circumference }^{\mathrm{b}}, \text { mean } \pm \mathrm{SE}\end{array}$ & $\begin{array}{c}\text { Protection Index, fold change } \\
\text { compared to vehicle-treated controls }\end{array}$ \\
\hline Vehicle & $6.5 \pm 0.9$ & - \\
$\mathrm{CR} 32942.5 \mathrm{mg} / \mathrm{kg}$ & $9.9 \pm 1.0$ & 1.5 \\
$\mathrm{CR} 32945 \mathrm{mg} / \mathrm{kg}$ & $11.7 \pm 2.5$ & 1.8 \\
CR3294 $10 \mathrm{mg} / \mathrm{kg}$ & $11.8 \pm 1.2$ & 1.8 \\
CR3294 $20 \mathrm{mg} / \mathrm{kg}$ & $18.1 \pm 1.9^{*}$ & 2.8 \\
\hline
\end{tabular}

Each treatment group comprised 8 mice

a 72,48 , and $24 \mathrm{~h}$ before $2 \times 450 \mathrm{mg} / \mathrm{kg} 5$-FU

${ }^{\mathrm{b}}$ Corrected number, expressed as the following ratio: (mean crypt width in untreated controls/mean crypt width in treatment group) $\times$ mean number of surviving crypts in treatment group

$* P<0.001$, Holm-Sidak method 

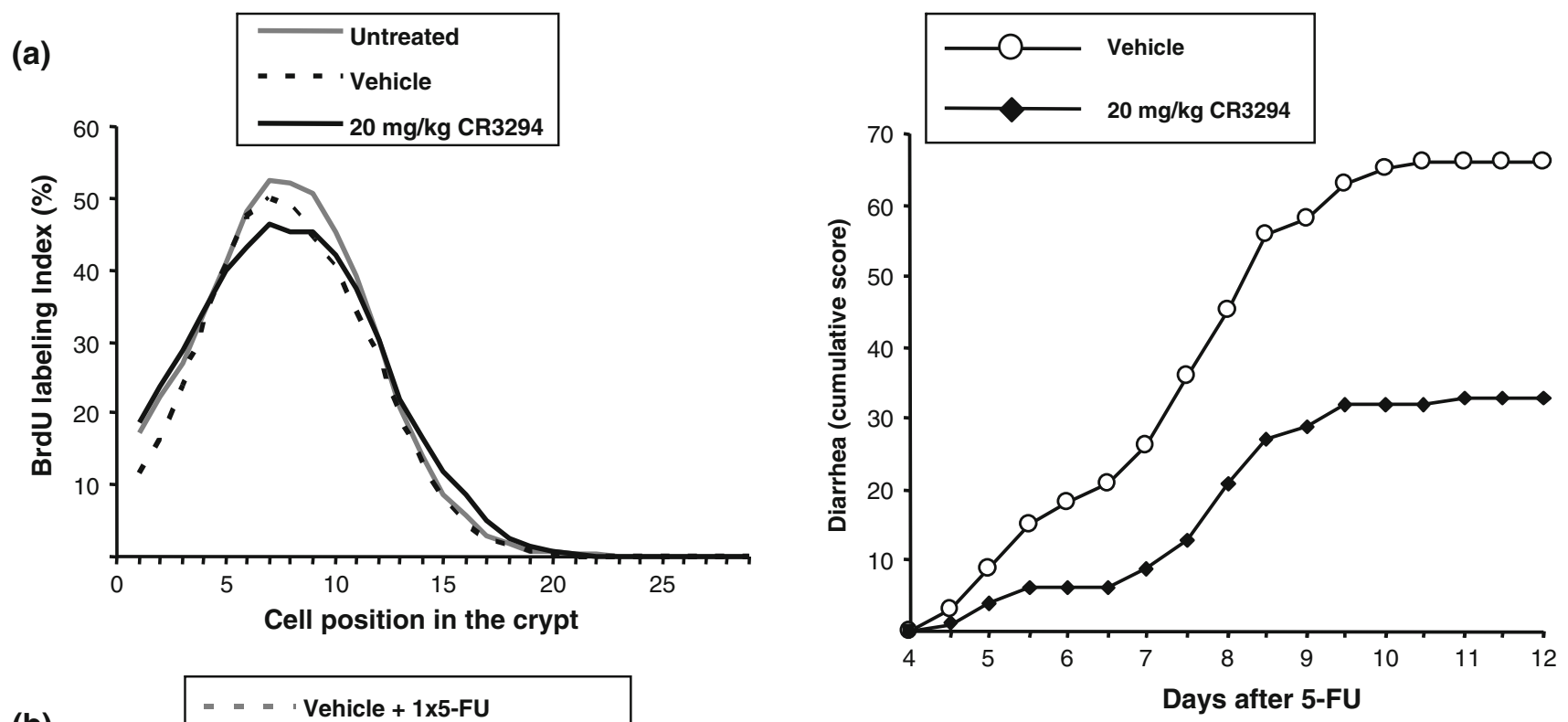

(b)

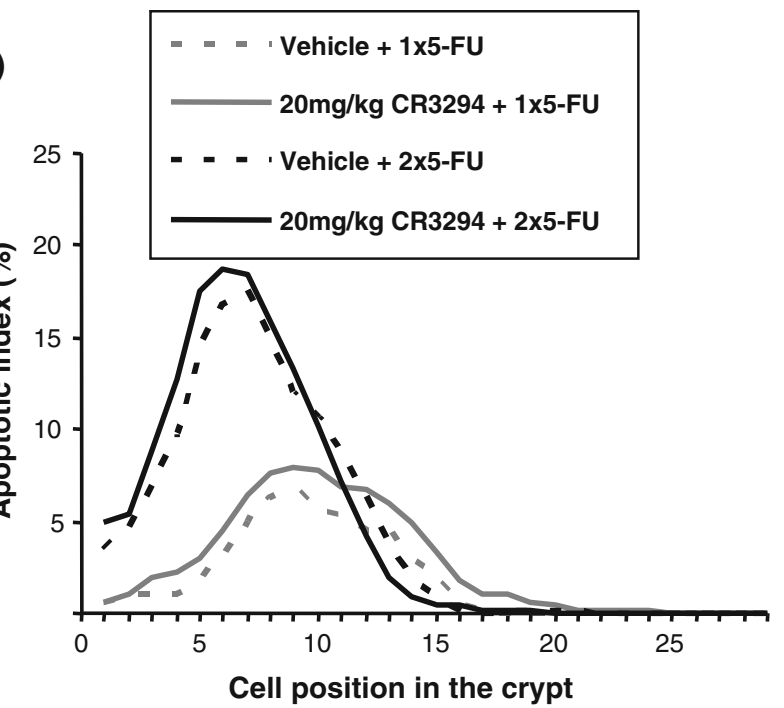

Fig. 3 Cumulative diarrhea score in mice exposed to 5-FU. Animals ( $n=15$ per group) were pretreated with CR3294 or its vehicle 72,48 , and $24 \mathrm{~h}$ before receiving 2 doses ( $6 \mathrm{~h}$ apart) of the cytotoxic agent. Scores were recorded as $0,1,2$, or 3 where 0 is normal stools, 1 is loose stools, 2 is moderate diarrhea, and 3 is severe diarrhea

CR3294 is an anti-inflammatory agent that inhibits the expression of iNOS and cyclooxygenase 2 (COX-2) [10]. Recent findings suggest a role for iNOS and COX-2 in the onset of mucositis [12, 14, 23]. However, it is widely accepted that ROS initiate the cascade of events-including increased levels of inflammatory cytokines-that leads to mucosal damage [12]. In this study, CR3294 inhibited the release of IL- $1 \beta$, IL- 6 , IL- 8 , and TNF- $\alpha$ from stimulated leukocytes at concentrations similar to those required to inhibit ROS production by these cells. The link between oxidative stress and mucositis is confirmed by other studies in which ROS scavengers were tested as protective agents against radiation-induced damage [24, 25]. Palifermin, the only drug approved for the treatment of oral mucositis, is a human keratinocyte growth factor (KGF) produced by recombinant DNA technology. In addition to stimulating epithelial cell proliferation, KGF activates the transcription factor NF-E2-related factor 2 (Nrf2), which in turn increases the expression of ROS-scavenging enzymes [26]. Because the use of anti-inflammatory agents is now regarded as a promising approach to reduce the severity of mucositis [27], there is a strong rationale for developing new drugs with combined ROS-scavenging and antiinflammatory properties. This is particularly relevant to GI mucositis, for which no therapy is currently approved although a variety of agents have been assessed in preclinical and clinical studies. Recently, alternative medicine approach gained attention. Probiotics have been shown to reduce intestinal inflammation and diarrhea in 


\section{Vehicle}

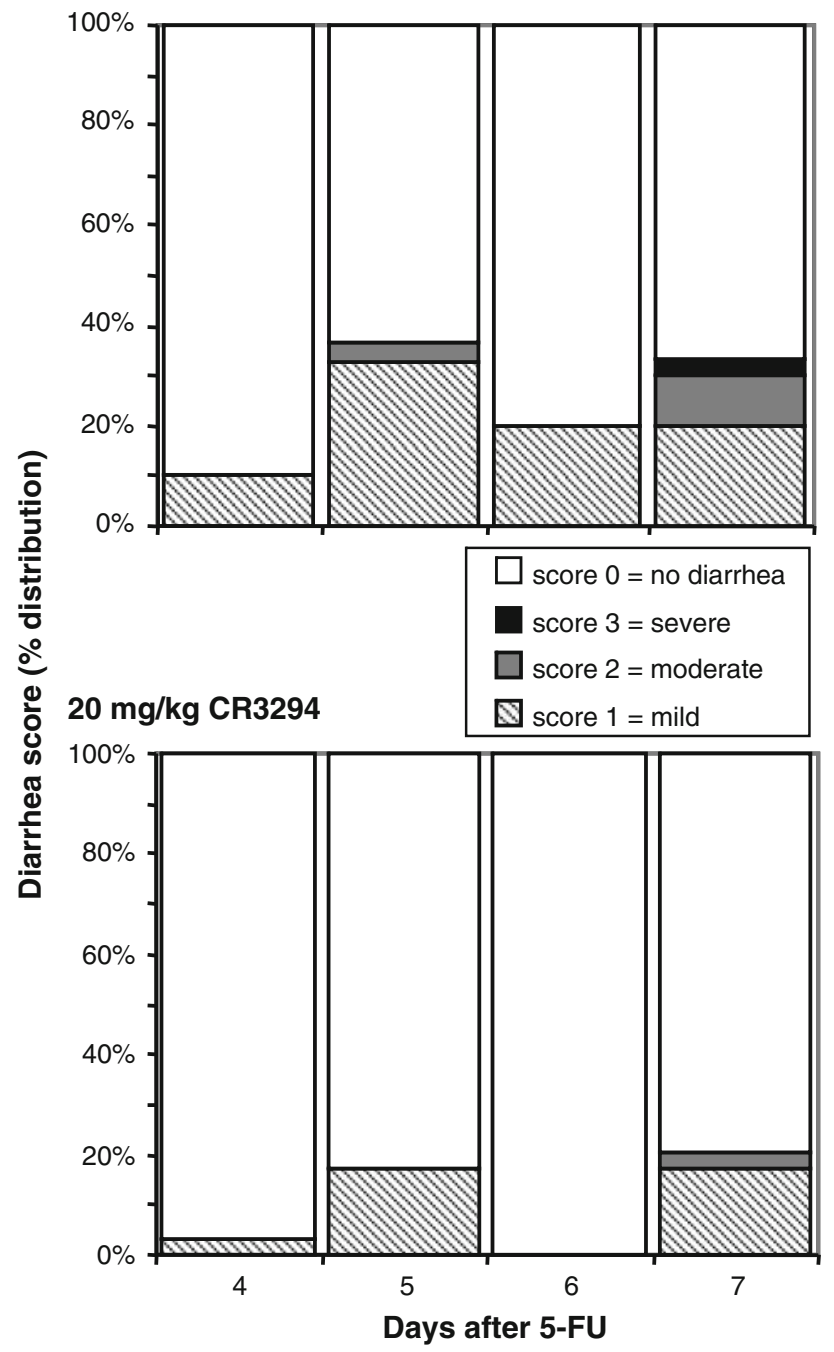

Fig. 4 Incidence of diarrhea by severity score. Animals $(n=15$ per group) were pretreated with CR3294 or its vehicle 72,48 , and $24 \mathrm{~h}$ before receiving 2 doses ( $6 \mathrm{~h}$ apart) of 5-fluorouracil (5-FU)

experimental models of GI mucositis in rats [28-30]. Herbal extracts, due to their anti-inflammatory and antioxidative properties and in keeping with CR3294 activity, have been shown to decrease mucosal damage in preclinical and clinical studies [31, 32].

The main goal of this study was to examine whether CR3294 has the potential to prevent GI mucositis and diarrhea. In a first set of in vivo experiments, we found that CR3294 significantly protected crypt cells against damage induced by 5 -FU. Conversely, no definite effects were seen in an experimental model of radiation-induced mucositis. Different factors could account for the lack of conclusive results in this experimental setting. First, the adopted protocol may be non-optimal. Further studies with different radiation schemes have been planned to test the above hypothesis. Additionally, because X-rays and 5-FU target different cells in the intestinal crypts [33], it is conceivable

\section{(a)}

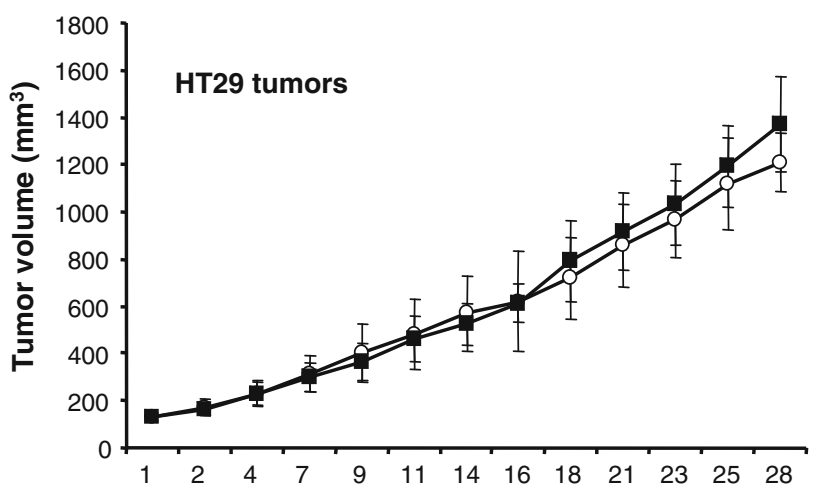

(b)
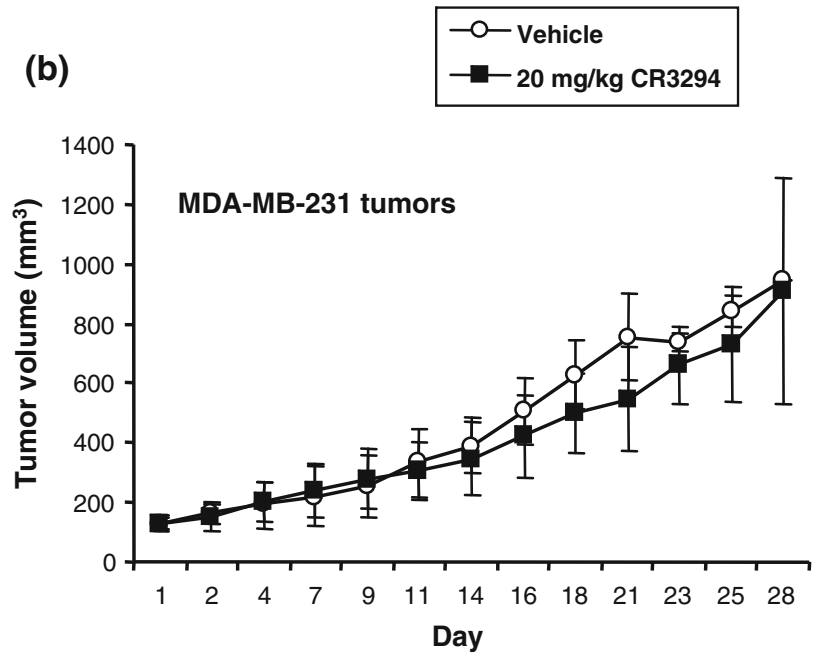

Fig. 5 Tumor growth curves in control and CR3294-treated groups. a Male BALB/c nude mice ( $n=8$ per group) were xenografted with human colorectal (HT29) cancer cells and treated with vehicle (sterile water) or CR3294 for 14 days. b Female mice ( $n=8$ per group) were xenografted with human breast (MDA-MB-231) cancer cells and treated with CR3294 or its vehicle for 14 days

that CR3294 protects a specific cell type in the crypt hierarchy. Unlike KGF, CR3294 did not stimulate epithelial cell proliferation, but similarly to KGF, the effectiveness of CR3294 was greatest when it was administered in a preventive mode [34]. This finding suggests that other mechanisms, besides ROS scavenging, contribute to the cytoprotective activity of this agent. One such mechanism may involve decreased sensitivity to 5-FU-induced apoptosis [35], but our experiments did not show significant differences in this regard. Alternatively, given that CR3294 can induce the formation of autophagosomes [10], it is possible that CR3294 increased crypt survival by activating the autophagic pathway. Autophagy may indeed serve as a rescue mechanism whereby cells extend their lifespan under critical conditions [36]. Although analyzing autophagyrelated processes was beyond the scope of our present work, studies are under way to test the above hypothesis. 


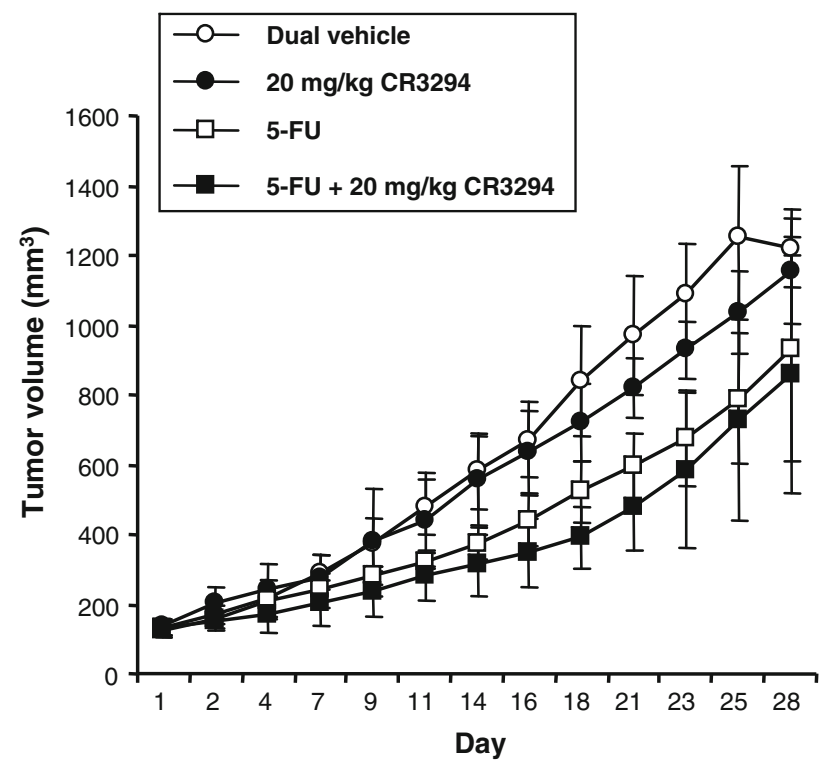

Fig. 6 Tumor response to 5-FU in the presence or absence of CR3294. Male BALB/c nude mice $(n=8$ per group) were xenografted with the colorectal HT29 cell line. CR3294 or its vehicle (water) was administered orally on days $1-3$ and $8-10$, whereas 5 -FU $(25 \mathrm{mg} / \mathrm{kg}$ ) or its vehicle (saline) was administered intraperitoneally on days $1-5$

Here, we were interested in assessing whether mucosal protection could translate into a lower incidence of diarrhea, because CID is associated with dose reductions, dose delays, and excess hospitalizations and deaths. In our proof-of-concept study, pretreatment with CR3294 halved the cumulative diarrhea score in mice exposed to 5-FU. CR3294 was particularly effective against moderate-tosevere CID: animals treated with the $20 \mathrm{mg} / \mathrm{kg}$ dose were $70 \%$ less likely to experience grade $2-3$ diarrhea than vehicle-treated mice. Severe diarrhea is common in patients receiving fluoropyrimidine-based chemotherapy $[4,6,37]$. In the absence of effective drugs to avoid this adverse event, treatment has superseded prevention in the clinical setting, and high-dose loperamide is used for managing mild-to-moderate diarrhea. Unfortunately, loperamide is far less effective when it comes to severe episodes, those that may be life threatening [7, 37, 38].

CR3294 did not improve animal survival, even though it slightly delayed the onset of death after exposure to 5-FU. However, our proof-of-concept study was designed to detect an effect of the compound on diarrhea rate and severity rather than on death from GI syndrome. Damage to the GI tract, if sufficiently serious, would cause death within 6-7 days, whereas none of the mice in our study died before day 8 after 5 -FU injection. So, mortality was presumably associated with damage to the hematopoietic system [39]; and clearly, CR3294 did not limit chemicalinduced toxicity to the bone marrow.
Likewise, CR3294 neither altered the antitumor activity of 5-FU nor affected the growth rate of tumor xenografts in both female and male mice. Candidate drugs for the prevention or treatment of mucositis must not protect tumors. For instance, other authors have demonstrated that palifermin does not stimulate the growth of tumors, even those expressing the KGF receptor [29, 40]. Regardless that CR3294 is unlikely to promote cell proliferation via KGFdependent mechanisms, we ruled out unexpected yet possible untoward effects. A recent study has even shown that CR3294 reduces tumor growth in vivo [10]. The variable results between that study and the present one might be due either to the different models used or to the different duration of treatment ( 8 vs. 2 weeks).

In summary, our experimental study demonstrates that CR3294 acts on critical mechanisms of mucosal injury to reduce the signs of GI mucositis as well as the incidence and severity of 5-FU-induced diarrhea. These positive results warrant further investigation in humans because no drugs are currently approved for the prevention of CID. Phase I clinical trials are now under way to evaluate the safety profile of CR3294.

Acknowledgments The authors thank Mr. Mario Montagna for technical support and Mrs. Laura Radaelli for secretary assistance. This study was funded by the Rottapharm Group. However, the Rottapharm Group as a corporate entity had no role in the conduct of the study; in the collection, analysis and interpretation of data; in the writing of the manuscript; and in the decision to submit the manuscript for publication. This work was part of a project co-financed in conjunction with the Italian Ministry of Health (Attività di ricerca finalizzata D. Lgs. 502/92).

Conflict of interest statement All authors except Catherine Booth are employees of Rottapharm S.p.A. Catherine Booth is an employee of EpiStem Ltd., a research organization under contract with the Rottapharm Group.

Open Access This article is distributed under the terms of the Creative Commons Attribution Noncommercial License which permits any noncommercial use, distribution, and reproduction in any medium, provided the original author(s) and source are credited.

\section{References}

1. Duncan M, Grant G (2003) Oral and intestinal mucositis-causes and possible treatments. Aliment Pharmacol Ther 18:853-874

2. Sonis ST, Elting LS, Keefe D, Peterson DE, Schubert M, HauerJensen M, Bekele BN, Raber-Durlacher J, Donnelly JP, Rubenstein EB (2004) Perspectives on cancer therapy-induced mucosal injury: pathogenesis, measurement, epidemiology, and consequences for patients. Cancer 100:1995-2025

3. Rubenstein EB, Peterson DE, Schubert M, Keefe D, McGuire D, Epstein J, Elting LS, Fox PC, Cooksley C, Sonis ST (2004) Clinical practice guidelines for the prevention and treatment of cancer therapy-induced oral and gastrointestinal mucositis. Cancer 100:2026-2046 
4. Leichman CG, Fleming TR, Muggia FM, Tangen CM, Ardalan B, Doroshow JH, Meyers FJ, Holcombe RF, Weiss GR, Mangalik A (1995) Phase II study of fluorouracil and its modulation in advanced colorectal cancer: a Southwest Oncology Group study. J Clin Oncol 13:1303-1311

5. Arnold RJ, Gabrail N, Raut M, Kim R, Sung JC, Zhou Y (2005) Clinical implications of chemotherapy-induced diarrhea in patients with cancer. J Support Oncol 3:227-232

6. Wisinski K, Benson A III (2007) Chemotherapy-induced mucositis: focusing on diarrhea. J Support Oncol 5:270-271

7. Rothenberg ML, Meropol NJ, Poplin EA, Van CE, Wadler S (2001) Mortality associated with irinotecan plus bolus fluorouracil/leucovorin: summary findings of an independent panel. J Clin Oncol 19:3801-3807

8. Bowen JM (2008) Prevention and treatment of regimen-related mucosal toxicity. Recent Patents Anticancer Drug Discov 3:68-75

9. Keefe DM, Sonis ST, Bowen JM (2008) Emerging drugs for chemotherapy-induced mucositis. Expert Opin Emerg Drugs 13:511-522

10. Tafani M, Schito L, Anwar T, Indelicato M, Sale P, Di VM, Morgante E, Beraldi R, Makovec F, Letari O, Caselli G, Spadafora C, Pucci B, Russo MA (2008) Induction of autophagic cell death by a novel molecule is increased by hypoxia. Autophagy 4:1042-1053

11. Makovec F, Zanzola S, Artusi R, Rovati LC (2007) Benzamidine derivatives having anti-inflammatory and immunosuppressive activity. Patent No. US7,202,277

12. Sonis ST (2004) The pathobiology of mucositis. Nat Rev Cancer 4:277-284

13. Logan RM, Gibson RJ, Bowen JM, Stringer AM, Sonis ST, Keefe DM (2008) Characterisation of mucosal changes in the alimentary tract following administration of irinotecan: implications for the pathobiology of mucositis. Cancer Chemother Pharmacol 62:33-41

14. Leitao RF, Ribeiro RA, Bellaguarda EA, Macedo FD, Silva LR, Oria RB, Vale ML, Cunha FQ, Brito GA (2007) Role of nitric oxide on pathogenesis of 5-fluorouracil induced experimental oral mucositis in hamster. Cancer Chemother Pharmacol 59:603-612

15. Al-Dasooqi N, Gibson RJ, Bowen JM, Keefe DM (2009) Matrix metalloproteinases: key regulators in the pathogenesis of chemotherapy-induced mucositis? Cancer Chemother Pharmacol 64:1-9

16. (1988) UKCCCR guidelines for the welfare of animals in experimental neoplasia. Br J Cancer 58:109-113

17. Withers HR, Elkind MM (1970) Microcolony survival assay for cells of mouse intestinal mucosa exposed to radiation. Int J Radiat Biol Relat Stud Phys Chem Med 17:261-267

18. Potten CS, Hendry JH (1985) The microcolony assay in mouse small intestine. In: Potten CS, Hendry JH (eds) Cell clones. Churchill Livingstone, Edinburgh, pp 50-60

19. Potten CS, Rezvani M, Hendry JH, Moore JV, Major D (1981) The correction of intestinal microcolony counts for variation in size. Int J Radiat Biol Relat Stud Phys Chem Med 40:321-326

20. Merritt AJ, Jones LS, Potten CS (1996) Apoptosis in murine intestinal crypts. In: Cotter TG, Martin SJ (eds) Techniques in apoptosis. Portland Press, London, pp 269-300

21. Potten CS, Owen G, Roberts SA (1990) The temporal and spatial changes in cell proliferation within the irradiated crypts of the murine small intestine. Int J Radiat Biol 57:185-199

22. Keefe DM, Schubert MM, Elting LS, Sonis ST, Epstein JB, Raber-Durlacher JE, Migliorati CA, McGuire DB, Hutchins RD, Peterson DE (2007) Updated clinical practice guidelines for the prevention and treatment of mucositis. Cancer 109:820-831

23. Sonis ST, O'Donnell KE, Popat R, Bragdon C, Phelan S, Cocks D, Epstein JB (2004) The relationship between mucosal cyclooxygenase-2 (COX-2) expression and experimental radiationinduced mucositis. Oral Oncol 40:170-176
24. Murphy CK, Fey EG, Watkins BA, Wong V, Rothstein D, Sonis ST (2008) Efficacy of superoxide dismutase mimetic M40403 in attenuating radiation-induced oral mucositis in hamsters. Clin Cancer Res 14:4292-4297

25. Facorro G, Sarrasague MM, Torti H, Hager A, Avalos JS, Foncuberta M, Kusminsky G (2004) Oxidative study of patients with total body irradiation: effects of amifostine treatment. Bone Marrow Transplant 33:793-798

26. Braun S, Hanselmann C, Gassmann MG, auf dem Keller U, BornBerclaz C, Chan K, Kan YW, Werner S (2002) Nrf2 transcription factor, a novel target of keratinocyte growth factor action which regulates gene expression and inflammation in the healing skin wound. Mol Cell Biol 22:5492-5505

27. Lalla RV, Schubert MM, Bensadoun RJ, Keefe D (2006) Antiinflammatory agents in the management of alimentary mucositis. Support Care Cancer 14:558-565

28. Bowen JM, Stringer AM, Gibson RJ, Yeoh AS, Hannam S, Keefe DM (2007) VSL\#3 probiotic treatment reduces chemotherapyinduced diarrhea and weight loss. Cancer Biol Ther 9:1449-1454

29. Smith CL, Geier MS, Yazbeck R, Torres DM, Butler RN, Howarth GS (2008) Lactobacillus fermentum BR11 and fructo-oligosaccharide partially reduce jejunal inflammation in a model if intestinal mucositis in rats. Nutr Cancer 60:757-767

30. Whitford EJ, Cummins AG, Butler RN, Prisciandaro LD, Fauser JK, Yazbeck R, Lawrence A, Cheah KY, Wright TH, Lymn KA, Howarth GS (2009) Effects of Streptococcus thermophilus TH-4 on intestinal mucositis induced by the chemotherapeutic agent, 5Fluorouracil (5-FU). Cancer Biol Ther 8(6):505-512

31. Cheah KY, Howarth GS, Yazbeck R, Wright TH, Whitford EJ, Payne C, Butler RN, Bastian SE (2009) Grape seed extract protects IEC-6 cells from chemotherapy-induced cytotoxicity and improves parameters of small intestinal mucositis in rats with experimentally-induced mucositis. Cancer Biol Ther 8:382-390

32. You WC, Hsieh CC, Huang JT (2009) Effect of extracts from indigowood root (Isatis indigotica Fort.) on immune responses in radiation-induced mucositis. J Altern Complement Med 15:771-778

33. Ijiri K, Potten CS (1987) Further studies on the response of intestinal crypt cells of different hierarchical status to eighteen different cytotoxic agents. Br J Cancer 55:113-123

34. Farrell CL, Bready JV, Rex KL, Chen JN, DiPalma CR, Whitcomb KL, Yin S, Hill DC, Wiemann B, Starnes CO, Havill AM, Lu ZN, Aukerman SL, Pierce GF, Thomason A, Potten CS, Ulich TR, Lacey DL (1998) Keratinocyte growth factor protects mice from chemotherapy and radiation-induced gastrointestinal injury and mortality. Cancer Res 58:933-939

35. Hwang PM, Bunz F, Yu J, Rago C, Chan TA, Murphy MP, Kelso GF, Smith RA, Kinzler KW, Vogelstein B (2001) Ferredoxin reductase affects p53-dependent, 5-fluorouracil-induced apoptosis in colorectal cancer cells. Nat Med 7:1111-1117

36. Yorimitsu T, Klionsky DJ (2005) Autophagy: molecular machinery for self-eating. Cell Death Differ 12(Suppl 2):15421552

37. Saltz LB (2003) Understanding and managing chemotherapyinduced diarrhea. J Support Oncol 1:35-46

38. Benson AB III, Ajani JA, Catalano RB, Engelking C, Kornblau SM, Martenson JA Jr, McCallum R, Mitchell EP, O’Dorisio TM, Vokes EE, Wadler S (2004) Recommended guidelines for the treatment of cancer treatment-induced diarrhea. J Clin Oncol 22:2918-2926

39. Potten CS (1996) Protection of the small intestinal clonogenic stem cells from radiation-induced damage by pretreatment with interleukin 11 also increases murine survival time. Stem Cells 14:452-459

40. Gibson RJ, Bowen JM, Keefe DM (2005) Palifermin reduces diarrhea and increases survival following irinotecan treatment in tumor-bearing DA rats. Int J Cancer 116:464-470 